-1309-1314;2010). To mate successfully with their chosen partners, Brennan says, female ducks assume a posture that allows males to enter them fully and deposit sperm near the eggs.

\section{CLOSE COMPETITION}

However, evolutionary changes in the size and shape of body parts are generally thought to happen over generations, not within an individual's lifetime. Brennan wondered whether ducks might buck this trend, because some species' penises emerge anew every breeding season and degenerate afterwards.

Brennan and her colleagues fenced off habitats so that ducks would live either in pairs or in groups with almost twice as many males as females for two breeding seasons over the course of two years. The lesser scaups grew longer penises when they were forced to compete for females than when they were coupled up. A larger reproductive organ is thought to improve their chances of fertilizing an egg.

But the results of the social environment on ruddy ducks were more complicated. During the first year, only the largest males grew long penises (about 18 centimetres each), whereas smaller males developed half-centimetre stubs. In the second year, smaller males grew normal-sized penises, but they lasted for just five weeks, whereas the largest males kept their penises for three months.

Clues may lie in the drama of ruddy-duck life. The birds have some of the largest penisto-body ratios found in nature - with penises that can be longer than their bodies. "I can't imagine they could grow any longer," Brennan says. The birds fight to the death at times, which suggests that smaller ones might be too stressed to develop penises normally. "Bullying may increase stress hormones, and those

\section{"There is a cost} to having a large penis because individuals are investing according to the competition." could counteract the effects of androgen hormones" that control penis growth, Brennan says.

This response to stress could be adaptive. The same androgen hormones

that trigger penis growth every season in birds also underlie colouration. They cause the duck's feathers to turn from dull brown to chestnut when it's time to breed, and their bills to go from grey to bright blue. To females, the wardrobe change signals a male's readiness. To neighbouring males, it foreshadows a fight. "I think the small ones go through it quickly so that there's less danger of getting beaten up," Brennan says.

The study is "really interesting", says Charlie Cornwallis, an evolutionary biologist at Lund
University in Sweden. "This suggests there is a cost to having a large penis because individuals are investing according to the competition they face from other males." Cornwallis says that few studies have investigated the effect of environmental and social conditions on penis size, and that these evolutionary trade-offs could be more common than imagined.

Visitors to the Livingston Ripley Waterfowl Conservancy in Litchfield, Connecticut, where the study was conducted, overlook the birds' bargains as well. "People watch the ducks on the weekends, but they have no idea what's really going on," Brennan says. "I now have a love-hate relationship with ducks."

\section{CORRECTIONS}

The News story 'Researchers unite in quest for 'standard model' of the brain' (Nature 549, 319-320; 2017) incorrectly located the Simons Foundation in Washington DC. It is in New York City.

Both the News story 'Researchers riled by lack of detail in Brexit science plans' (Nature 549, 140-141; 2017) and the Seven Days item 'Brexit plans' (Nature 549, 137; 2017) erroneously stated that the United Kingdom would leave the European Union next year. In fact, it is expected to leave in 2019. 